\title{
Evaluation of Visualization Interfaces Data Reporting on Mobile Devices
}

\author{
Roger Quispe, Jhon E. Monroy, Roni G. Apaza, and José A. Herrera
}

\begin{abstract}
The paper describes the use of visual interfaces whose main purpose is to represent a set of minimum entropy data to an end user. The aim of this paper is to study and evaluate existing visualization interfaces and determine which of them are ideal for adoption in mobile devices, in order to achieve this we compare traditional visual metaphors as bar, map, treemap, linear and circular graphics. We detail the main advantages of each of the types of data visualization. We have identified through usability techniques that the adoption of different characteristics of each visual metaphor points to a circular interface circular as having features for handling hierarchical and multivariate data. In other metaphors, an aesthetics analysis is also made; the results are presented in comparative tables.
\end{abstract}

Index Terms-Visualization, metaphors, circular interface, mobile devices, hierarchical data and multivariate data usability.

\section{INTRODUCTION}

Information visualization is an emerging area of interest of transversal and interdisciplinary character [1]. An important dimension of the problem is that which relates access to large volumes of information with the generation of knowledge [2], since large volumes of information processed by computer must demonstrate relevant and effective information on short reports that are appropriate for rapid decision-making by observant [3] users. These visualization representations must therefore be adapted to concepts of usability [4].

What visualization representations are better perceived and used by end-users? What aspects of cognition and perception influence learning to understand the visuals that display information on mobile devices? These and other questions are faced in this work.

To address the problem this quantitative descriptive research was developed which allows, through the use and evaluation of survey results, to establish which visualizations are the most appropriate when used on mobile devices. The surveys will be completed by a sample of teachers and assistants schools in the department of Arequipa Peru.

Manuscript received October 9, 2016; revised March 15, 2017.

Jhon E. Monroy Barrios was with the Department Concytec in TIC's, of the National University of Saint Augustine, U.S.A (e-mail: jhoedmon@gmail.com).

Roger Quispe Riquelme and Roni G. Apaza Aceituno are with the National University of San Agustin, U.S.A

Jose A. Herrera Quispe is with the Professional School of Computer Science of the National University of Saint Agustin, U.S.A
The research results may be applied in the construction and adaptation of applications on mobile devices, thus time and resources will be saved by identifying the strengths and weaknesses of each visualization interface. The article was divided into three parts which consist of theoretical framework, comparison and discussion.

\section{THEORETICAL FRAMEWORK}

We understand by information visualization the use of interactive interfaces whose main purpose is to represent with minimal visual entropy a series of data to an end user [5]-[7]. Information visualization is characterized by:

- Transforming raw data into relevant information.

- Find the minimum loss of information in this transformation.

- Target users interact, transform and interpret this information.

The first feature that captures the essence of the information visualization is the value of data as a basis for presenting them through visual metaphors. There are several advantages to represent data using metaphors, such as increasing human memory and cognitive analysis, among other characteristics studied [8].

The second feature refers to entropy, that is, the amount of information loss when transmitting data in a communication channel and render it in metaphors [9].

The third feature focuses on Human-Computer Interaction. The importance of including the human operator in the definition of Information Visualization is that all appropriate visualization process should be aware of the perceptual limitations of the human being, and his or her experience with the device.

It is understood that by viewing information as communication interface between user and data, it is possible to understand the importance of design visualization environments (metaphors) through analysis detailing their individual advantages and disadvantages for use on mobile devices.

\section{A. Bar}

Bar graphics are one of the most common ways to visualize data because the comparison of information is fast, high and low points are revealed to the naked eye. Bar charts are especially effective when you have numeric data that are divided neatly into different categories so that you can see, quickly, trends in the data [10].

Advantages:

- Helps the user to quickly compare the related information, rather than go a lot of information to answer a question. 
- The colors in the bars give greater impact. Overlapping colors to present information provides immediate understanding.

- To use stacked bar or bars side by side. Related data visualization on top or next to each part, provides depth analysis and addresses multiple questions at once.

Disadvantages:

- Their demand use large amount of screen space as working with multiple variables.

- The presentation of multiple data require a threedimensional space.

\section{B. Line}

Line charts connect individual points of numerical data and the result is simple and displays a sequence of values [11].

Advantages:

- The main use is the visualization of trends over a period of time.

Disadvantages:

- It makes use of a lot of space on the screen leaving unused pixels.

- Limitations in combining of multiple variables.

- Exploring its detail is complicated.

C. Circle

Circles graphics should be used to show relative proportions or percentages information. The number of elements compared in a pie chart may be large [12].

Advantages:

- The simple presentation of information makes it accessible to users of all ages and educational levels.

- Your understanding is immediately by the user of what you're trying to communicate.

- The space management is optimal.

Disadvantages:

- It is not easy to plot multiple data.

- The distribution on segments often produces overlap.

D. Map

When some kind of location data is had, like country names or custom geocoding, we prefer to see the data on a map [13].

Advantages:

- Viewing geocoded data.

- Easy management of geo located.

Disadvantages:

- Use is limited to location information.

- Difficulty of handling multiple variables.

- Its abstraction is confusing for new users.

\section{E. Treemap}

The treemap are perfect for displaying large amounts of data in a hierarchical structure (tree structure), the display space is divided into rectangles that are assigned a size and an order based on a quantitative variable. Levels of a treemap hierarchy are displayed as boxes containing other boxes [14].

Advantages:

- Handling multiple data.

- It employs the most of the screen space.

- Data management in a hierarchical fashion.

Disadvantages:
- Difficulty compression to the naked eye.

- The presentation of multiple data is unclear.

- The subdivision lot produces eyestrain.

\section{F. Aesthetics}

It refers to a visually pleasing design. It should be simple, i.e., facilitate the work without causing distractions. In the following items the corresponding sub-features are as follows:

Source: the font type and size is very important. That is, the shape and size of the font should be readable type and size of letters used in the interface.

Colors: refers to emphasize how important without overloading the vision. It is advisable to use between 4 and 7 colors to avoid eyestrain [2], [15], especially strong light tones reserving for important information. The combination of colors should be distinguishable if desired separate information. The attributes used to measure this feature are:

- Which colors are used.

- Harmonious combination.

- Predominantly light colors.

\section{COMPARISON}

For the presentation of information on mobile devices whose optimum size does not exceed 10 inches [16], it is necessary to meet requirements that none of the traditional graphics meet, so it is necessary to unify the most outstanding components to define an appropriate metaphor, we can mention the main ones:

- Use of screen size.

- Handling multiple variables.

- Hierarchical data management.

- Adaptable Aesthetics.

- Do not cause eyestrain.

Therefore it is determined that the graph in treemaps, circular rods meet the requirements for what must be to unify a metaphor based on the 3 traditional graphics.

- Manage hierarchical data as do Treemaps.

- Manage space in a pie chart.

- Manage variables as the bar graph.

- Use of easily distributable colors for circular and bar graphics.

- Avoid eyestrain graphic circle.

TABLE I: TYPE SIZES FOR CAMERA-READY PAPERS
\begin{tabular}{|l|r|r|r|r|r|}
\hline & Bar & Linear & Circle & Map & Treemap \\
\hline $\begin{array}{l}\text { Multivariable } \\
\text { presentation }\end{array}$ & 1 & & & & 1 \\
\hline Use of space & & & 1 & & 1 \\
\hline $\begin{array}{l}\text { Temporary } \\
\text { presentation }\end{array}$ & & 1 & & & \\
\hline Easy explanation & & & 1 & 1 & 1 \\
\hline Simple presentation & & 1 & 1 & & 1 \\
\hline Low entropy & 1 & & 1 & & 1 \\
\hline Under overlap & 1 & & 1 & 1 & 1 \\
\hline $\begin{array}{l}\text { Hierarchical } \\
\text { presentation }\end{array}$ & & & & 1 & 1 \\
\hline $\begin{array}{l}\text { Presence of } \\
\text { eyestrain }\end{array}$ & & & & & \\
\hline
\end{tabular}

It is determined that no metaphor meets the requirements to visualize the data, therefore it is necessary that a new 
metaphor meets the requirements of handling raw data. In Fig. 1 we can see the unused space on the screen of the mobile device, you can see that in the bar graph wastes more than $60 \%$ of screen space, the circular graphic wastes $22 \%$ while the treemap chart uses the entire screen space.

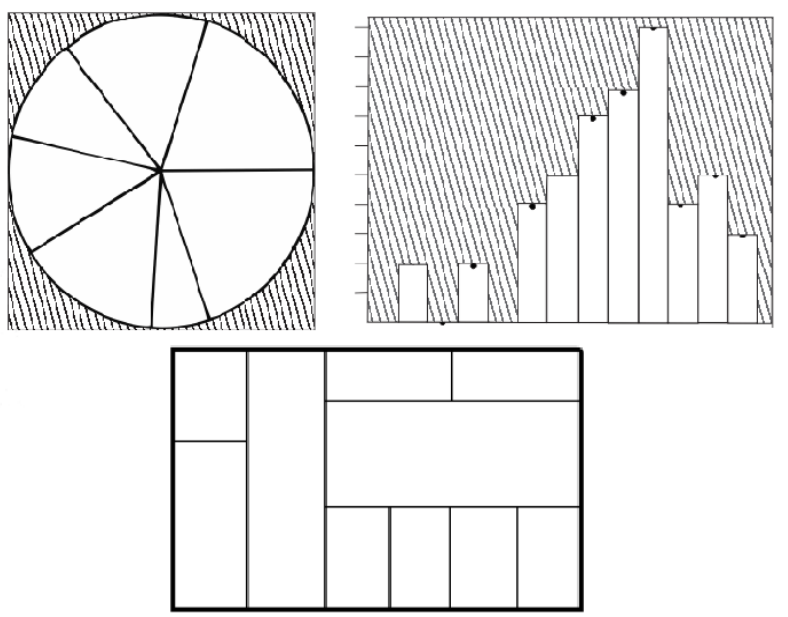

Fig. 1. Space metaphor on screen.

To meet the requirements it is determined that the pie chart incorporating the attributes of bar graphs and treemap presents an appropriate hierarchical management through layers that can be seen in Fig. 2 and internal to handle multiple variables distribution, this can be observed in Fig. 3

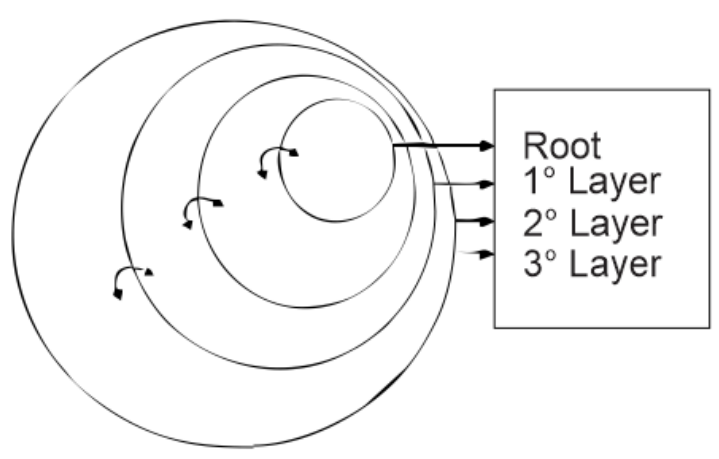

Fig. 2. Management layers in a circle metaphor.

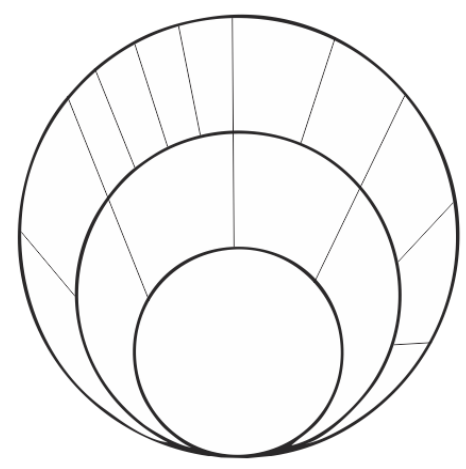

Fig. 3. Distribution for handling multiple variables.

In Fig. 4 we can observe the distribution on the screen of a mobile device, it must use the maximum space and produce no overlap.

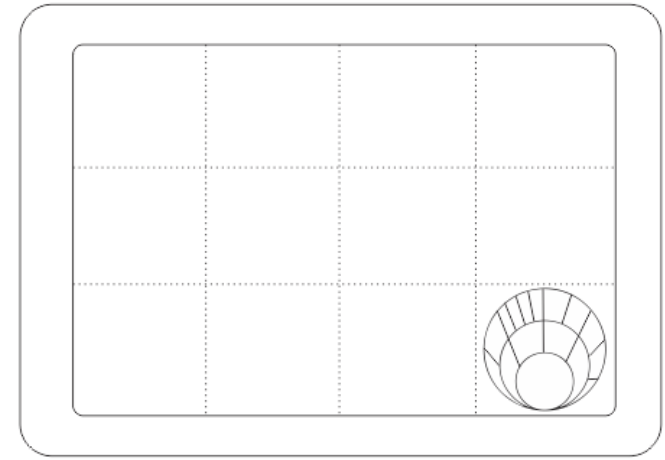

Fig. 4. End metaphor user in mobile.

\section{CONCLUSIONS}

The proper use of a information visualization metaphor showing users quick and concise information to avoid visual entropy makes the circular multilevel metaphor appropriate to present information, although not all advantages of traditional graphics are satisfied it does encompass most of them and can be applied by developers and people interested in the subject.

\section{ACKNOWLEDGMENT}

Thanks to CONCYTEC for supporting the development of technology and scientific research of the country.

\section{REFERENCES}

[1] Z. Pousman, J. T. Stasko, and M. Mateas , "Casual information visualization: Depictions of data in everyday life," IEEE Transactions on Visualization and Computer Graphics, vol. 13, no. 6, pp. 11451152, 2007.

[2] G. Grinstein and H. Levkowitz, (Eds.), "Perceptual issues in visualization," Springer Science \& Business Media, 2013.

[3] P. Moreno-Ger, J. Torrente, Y. G. Hsieh, and W. T. Lester, "Usability testing for serious games: Making informed design decisions with user data," Advances in Human-Computer Interaction, April 2012.

[4] M. A. Kuhail, S. Lauesen, K. Pantazos, and X. Shangjin, "Usability analysis of custom visualization tools," SIGRAD, pp. 19-2, November 2012.

[5] D. Keim, F. Mansmann, J. Schneidewind, and H. Ziegler, "Challenges in visual data analysis," IEEE Tenth International Conference on Information Visualization, IV 2006, pp. 9-16, July 2006.

[6] Purchase, H. C., Andrienko N., Jankun-Kelly T. J., and Ward M., "Theoretical foundations of information visualization," Information Visualization, Springer Berlin Heidelberg, pp. 46-64, 2008.

[7] R. Mazza, Introduction to information visualization. Springer Science \& Business Media, 2009.

[8] M. Brehmer and T. Munzner, "A multi-level typology of abstract visualization tasks," IEEE Transactions on Visualization and Computer Graphics, vol. 19, no. 12, pp. 2376-2385, 2013.

[9] C. Ware, "Information visualization: perception for design," Elsevier, 2012.

[10] R. M. Heiberger and N. B. Robbins, "Design of diverging stacked bar charts for Likert scales and other applications," Journal of Statistical Software, vol. 57, no. 5, pp. 1-32, 2014.

[11] W. Huang, C. L. Tan, and W. K. Leow, "Model-based chart image recognition," Graphics Recognition, Recent Advances and Perspectives. Springer Berlin Heidelberg, pp. 87-99. 2003.

[12] F. B. Viégas and J. S. Donath, "Chat circles," in Proc. of the SIGCHI conference on Human Factors in Computing Systems, pp. 9-16, May 1999.

[13] R. E. Voorrips, "MapChart: Software for the graphical presentation of linkage maps and QTLs," Journal of Heredity, vol. 93, no. 1, pp. 7778, 2002.

[14] R. Vliegen, Van Wijk, J. J., Van der Linden, and E. J., "Visualizing business data with generalized treemaps," IEEE Transactions on Visualization and Computer Graphics, vol. 12, no. 5, pp. 789-796. 2006. 
[15] L. Mol, "The potential role for infographics in science communication," Master Thesis Communication specialization (9 ECTS), Biomedical Sciences, Vrije Universiteit Amsterdam, 2011.

[16] R. Quispe and Monroy, "An evaluation of ergonomic factors in children interaction with mobile devices," Nuevas Ideas en Informática Educativa TISE, 2015.

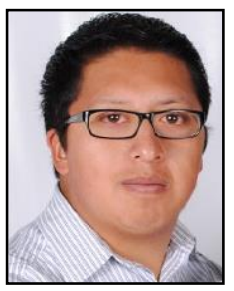

Roger Quispe Riquelme is a specialist in statistics and human computer interaction, testing statistical analysis. He has a Masters culminated in management in information technology at the National University of San Agustin, Conciliator Extrajudicial the Ministry of Justice, making a specialty in Scientific Research and Educational technology at the CREA - higher Institute Jose Antonio Echeverria, Cuba. Concytec currently pursuing a master for graduate studies are full time in Informatics at the National University of San Agustin.

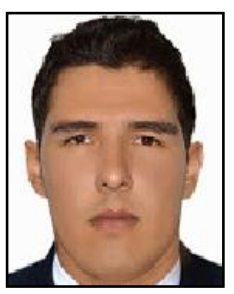

Jhon E. Monroy Barrios has professional skills to participate successfully in the design, development, implementation and maintenance of applications or information systems with specialization and expertise in IT, conducting studies of Educational Technology at the CREA - ISPAJAE, Cuba. He is currently a researcher at the Department CONCYTEC in TIC`s, of the National University of Saint Augustine where he participated in projects funded by FONDECYT FINCYT and in the areas of Human Computer Interaction and educational Computing.

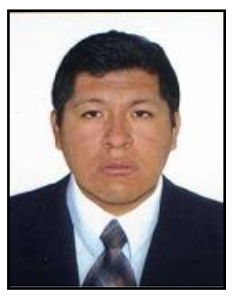

Roni G. Apaza Aceituno was a systems engineering graduate pela National University of San Agustin (2006). He got the master degree of computer science, title obtained in Institution of computer science and computational mathematics at the University of São Paulo (2013). He has experience in the area of computer science with an emphasis in distributed systems and education, also development related to Artificial Intelligence and the development of web content applications, apply measurement tools networks on new protocols currently interested in networks and internet communications, computer education, education and education programming in the use of tools with free licenses, especially tools with GPL (General Public license) licenses.

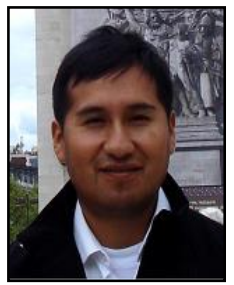

Jose A. Herrera Quispe is a doctor in computer science with research in hydro-informatics, intelligent systems and systems e-learning, made his specialty in the CNRS, LMTG University Paul Sabatier in France. He earned his doctorate with a scholarship from the CONCYTEC in UNSA, in his research work proposed a new stochastic model for the generation of time series of hydrometeorological variables using similarity search and case-based reasoning, modeling work performed and prognosis of physical phenomena in the basin of Chili. His master work is linked to educational technology, proposing a model of intelligent content recommendation from the student learning styles using data mining; conducting studies of Educational Technology at the CREA - ISPAJAE, Cuba. He is currently principal investigator at the Department CONCYTEC in TIC's, general coordinator of the master in computer science from UNSA, secretary of IEEE computer society - Peru and professor at the Professional School of Computer Science of the National University of Saint Agustin, which it has funded projects and FONDECYT FINCYT in the areas of artificial intelligence, hydroinformatics, human computer interaction and educational computing. 